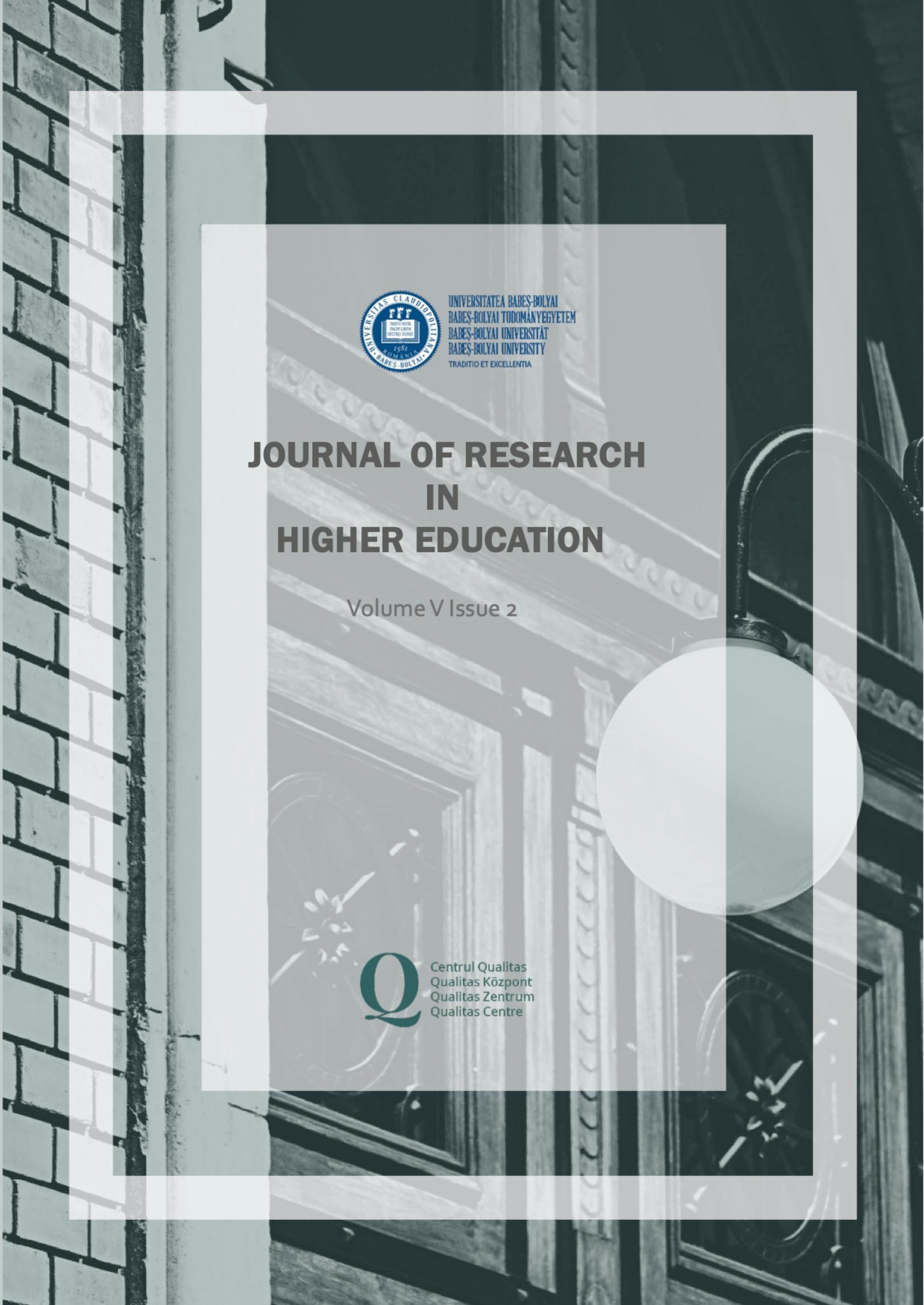




\section{Journal of Research in Higher Education}

- Vol. V, No. 2, 2021

Published twice yearly by

(C) Qualitas Centre, University Babeș-Bolyai

ISSN 2559 - 6624

ISSN-L 2559 - 6624

https://doi.org/10.24193/JRHE.2021.2 
Edited by: Qualitas Centre, Babeş-Bolyai University

\section{Editor-in-Chief}

Prof. Dan Chiribucă, University Babeş-Bolyai, Cluj-Napoca, Romania

Prof. Ioana Bican, University Babeş-Bolyai, Cluj-Napoca, Romania

\section{Editorial Board}

Professor Daniel David, University Babeş-Bolyai, Romania

Professor Markó Bálint, University Babeș-Bolyai, Romania

Professor Adrian Hatos, University of Oradea, Romania

Associate Professor William Yat Wai Lo, Hong Kong Institute of Education, China Professor Ian McNAY, University of Greenwich, UK

Associate Professor Bogdan Nadolu, West University of Timișoara, Romania, President of Romanian Sociologists Society

Professor Marian Preda, University of Bucharest, Romania

Professor Horațiu Rusu, Lucian Blaga University of Sibiu, Romania

Associate Professor Pedro Teixeira, University of Porto, Portugal

Professor Robert Toutkoushian, University of Georgia USA

Professor Eyüp Artvinli, Eskisehir Osmangazi University, Turkey

\section{Executive Editors}

dr. Simona Mălăescu

drd. Borbála Nemes

drd. Ionuc Pop

\section{Language Editors}

drd. Borbála Nemes

drd. Ionuc Pop

\section{(C) Cover design}

Simona Mălăescu

All material copyright (C)2021 by the Qualitas Centre, University BabeșBolyai. Reproduction or use without written permission is prohibited.

e-mail: journal.rehe@ubbcluj.ro

http://jrehe.reviste.ubbcluj.ro/ 


\section{Contents}

Ioana Bican

Introduction

5

Marcela Sălăgean

The topicality of the messages of the interwar Cluj rectors

7

Doru Cristian Todorescu 1940 - Transylvanian Institutions and Personalities Promoting Romanian Culture after the Vienna Arbitration

Marius Mureșan

The Visits of the Romanian Royal Family to the University of Cluj in the Interwar Period

Ana-Maria Stan

Academic Sociability in the interwar period - the example of "Andrei Saguna" maial festivity of Braşov settlers in Cluj 